\title{
Composition and Microstructure of the Al-Multilayer Graphene Composites Achieved by the Intensive Deformation
}

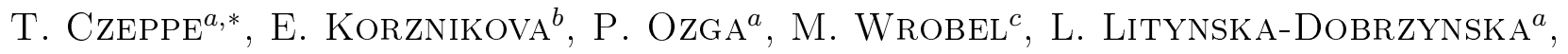 \\ G.F. KorzniKova ${ }^{b}$, A.W. KORZNIKOV ${ }^{b}$, P. CzAJA And R. SOCHA ${ }^{d}$ \\ ${ }^{a}$ Institute of Metallurgy and Materials Sciences, Polish Academy of Sciences, Kraków, Poland \\ ${ }^{b}$ Institute for Metals Superplasticity Problems, Russian Academy of Sciences, Ufa, Russia \\ ${ }^{c}$ AGH University of Science and Technology, Krakow, Poland \\ ${ }^{d}$ Institute of Catalysis and Surfaces Chemistry, Polish Academy of Sciences, Kraków, Poland
}

\begin{abstract}
The paper presents results of the studies concerning aluminum-graphene composites produced with use of step technique; first mechanical alloying of $\mathrm{Al}$ and graphene powders and later intensive deformation by the high pressure torsion. As a result small, thin and round samples of composites, about $10 \mathrm{~mm}$ in diameter were achieved. For comparison similar samples not containing graphene were investigated. The X-ray diffraction, transmission electron microscopy, Raman spectroscopy and X-ray photoelectron spectroscopy were applied to study composites structures and analyze graphene content and atomic bonds. The Raman spectroscopy method suggested multilayer graphene, which could also be identified as the defected nano-graphite as a component of the composite structure as well as some small content of the aluminum carbides. The highly dispersed microstructures of aluminum matrices were identified with the transmission electron microscopy, showing difference between the samples produced with the increased number of rotations, leading to the increased deformation realized. This method revealed carbon and aluminum oxides in large amounts which is interpreted as a surface effect. This method suggested also formation of the carbon-metal and carbon-metal- oxygen atomic bonds, which might partially result from formation of the carbides.
\end{abstract}

DOI: $10.12693 /$ APhysPolA.126.921

PACS: 81.05.Ni, 81.05.uj, 81.05.ue, 81.05.uf

\section{Introduction}

From the time when the method of a monolayer graphene preparation was published by Geim, Novoselov et al. [1-3] the scientific activity concerning the properties, production and application of this special form of carbon is very intensive. Graphene is two-dimensional (2D) crystalline material, stable in a wide temperature range, possessing unusual electronic, electrical, thermal and mechanical properties $[1,4-6]$. Particularly, the high electron mobility end electrical conductivity of graphene makes graphene a promising material for the future application in electrical devices [7]. Similarly, the mechanical properties like extremely high strength of the order of $42 \mathrm{~N} / \mathrm{m}$, related to the large intrinsic strain $\approx 25 \%$ and Young's modulus $\approx 1.0 \mathrm{TPa}[8]$ may be used for strengthening of composite materials. The interest in the graphene properties also re-emerged interest in the graphite oxide, which is a precursor for the mass production of the graphene-based materials [9] and also may be interesting as a part of composite structures.

Consequently, the application of the graphene is one of new, current subjects in materials sciences. The main effort concerns new graphene based electronics [10], catalysis and composite structures including polymers and graphene or graphite oxides. Less effort was done in

${ }^{*}$ corresponding author; e-mail: t.czeppe@imim.pl the range of the metal matrix composites, in which case graphene particles may improve electrical conductivity or/and strength of the material.

The following paper presents results of the study concerning aluminum-graphene composite produced with use of one of the severe plastic deformation techniques, high pressure torsion (HPT). The HPT was successfully used for the formation of the unique microstructure in case of the metals and alloys [11]. Such microstructure consists on small grains from micro- to nanosize. It was also used for the powder consolidation, especially in case of the amorphous glass or amorphous-crystalline composites [12]. The great advantage of the method is lack of the temperature increase, however sometimes unexpected metastable phase composition may be formed [13]. The main disadvantage is limited by the anvils, rather small sample size available.

\section{Experimental}

For the matrix of composite $\mathrm{Al}$ powder of the purity 99.99 , with particles size approximately $1 \mu \mathrm{m}$ was used. Two procedures of $\mathrm{Al}$ powder consolidation were used. First, the powder was consolidated directly by the HPT. Some preliminary attempts let to choose $4 \mathrm{GPa}$ hydrostatic pressure and 5 rotations. The second procedure included mechanical alloying (MA) in a ball mill. The planetary ball mill (type PM 400 from Retsch) was used in the experiment. Later similar HPT process was performed. On the base of the results concerning consolidation of the $\mathrm{Al}$ powders the second procedure 
was chosen for the Al-graphene composite production. In this case two from four grinding stations available in the equipment were charged during milling process. One vial was charged with Al powder and special steel balls with ball-to-powder weight ratio of $20: 1$, the total mass of the powder was $89.97 \mathrm{~g}$. The opposite tank was loaded with the same amount of powder with $0.05 \mathrm{wt} \%$ addition of the graphene. The graphene containing product was produced by the Novosibirsk Scientific Center of Siberian Branch of Russian Academy of Sciences.
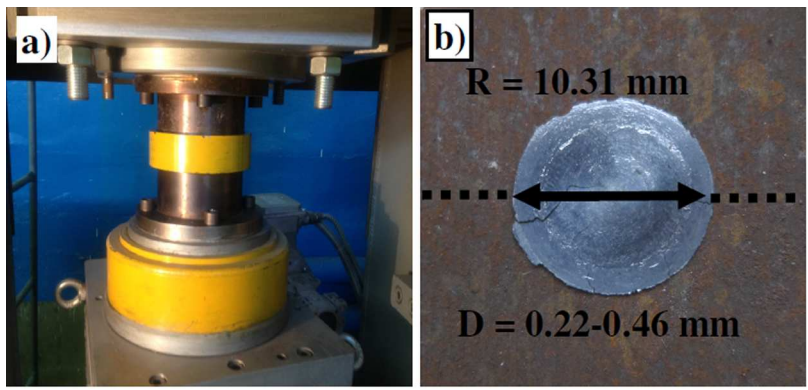

c)

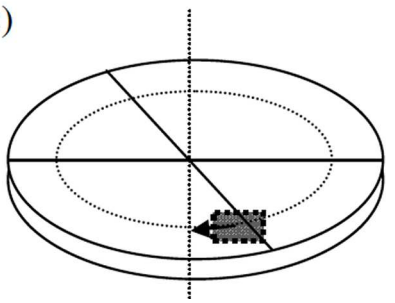

Fig. 1. (a) HPT equipment on the base of hydraulic press DE-2430-01, (b) the typical sample produced by the HPT, (c) position of the thin foil samples used for the TEM and HRTEM observations.

The ball milling was performed up to $7.5 \mathrm{~h}$, in the air atmosphere with $150 \mathrm{rpm}$ speed. To avoid the increase of the temperature, the milling was stopped after each 1 min of the work and the vials were cooled down for $30 \mathrm{~s}$. Subsequently HPT consolidation was applied. A small amount of powder was placed on the unconstrained type anvils with $10 \mathrm{~mm}$ diameter (Fig. 1a). 5 rotations at the pressure level of $4 \mathrm{GPa}$ were performed. As a result homogeneous, bulk samples in form of the thin discs about $10 \mathrm{~mm}$ in diameter were achieved. The HPT method was further modified and 10 rotations was also applied with the same hydrostatic pressure like before. The typical sample is shown in Fig. $1 b$ and the procedures summarized in Table I. The samples prepared in a different way were compared with use of the results of XRD and microhardness, which was measured in the center and at the edge of the samples (Table I).

The samples containing graphene were investigated with X-ray diffraction (XRD), scanning electron microscopy (SEM), and atomic force microscopy (AFM) to identify macro- and microstructure. The Raman spectroscopy was used to identify graphene content. For the precise investigation of microstructure the transmission electron microscopy (TEM) was used. For this type of investigations thin foils were cut and polished with use
TABLE I

Summary of the applied methods of the sample production and comparison of the sizes of the Scherrer's diffraction domains, relative compression $\Delta D / D$ and microhardness measured in two points ( $\mathrm{Gr}$ - graphene). \#1 - Sample, \#2 - Mechanical synthesis: time [min], \#3 - HPT: hydrostatic pressure/rotation number [GPa/N], \#4 - Size of the Scherer's diffraction domains [nm], \#5 $-\Delta D / D$ [\%], \#6- $\mu \mathrm{HV}$, center [GPa], $\# 7-\mu \mathrm{HV}$, edge [GPa].

\begin{tabular}{l|c|c|c|c|c|c}
\hline \hline \multicolumn{1}{c|}{$\# 1$} & $\# 2$ & $\# 3$ & $\# 4$ & $\# 5$ & $\# 6$ & $\# 7$ \\
\hline $\mathrm{Al}$ consol. & 0 & $4 / 5$ & 40 & 32 & 0.9 & 1.6 \\
$\mathrm{Al}$ consol. & 300 & $4 / 5$ & 100 & 47 & 1.5 & 2.0 \\
$\mathrm{Al}+0.05$ wt $\% \mathrm{Gr}$ & 300 & $4 / 5$ & 95 & 47 & 1.5 & 2.0 \\
$\mathrm{Al}+0.05$ wt\% Gr & 300 & $4 / 10$ & - & - & - & -
\end{tabular}

of the fine ion beam (FIB) technique. The orientation of the foils in relation to the sample is shown in Fig. 1c. As is visible, the plane of the foils was perpendicular both to the diameter and to the gradient of deformation. The foils were cut from the places at the edge of the samples, where deformation was near to the maximal. Micro-Raman spectra were taken using a Renishaw inVia Raman microscope $(50 \times$ or $100 \times$ objectives $)$ with $633 \mathrm{~nm}$ He-Ne excitation laser and 100\% laser power (21 mW output power), with spatial resolution better than $1 \mu \mathrm{m}$. The experiments with photoelectron spectroscopy (ESCA/XPS) were performed with hemispherical analyser SES R4000 (Gammadata Scienta) and excitation by the $\mathrm{Al} \mathrm{K} \alpha(1486.6 \mathrm{eV})$ lamp of the $200 \mathrm{~W}$ power. In the energy scale resolution for the $\mathrm{Ag} 3 d_{5 / 2}$ line was $1.0 \mathrm{eV}$, the measurements were performed in vacuum $3 \times 10^{-9}$ mbar. The surface layer was removed by the Ar ion etching in 10 min period with the parameters: $1.2 \mathrm{kV}, 10 \mathrm{~mA}$ and under $2 \times 10^{-6}$ mbar Ar pressure.

\section{Results and discussion}

The homogeneously consolidated bulk samples from the $\mathrm{Al}$ and graphene powders were produced by both procedures. As is shown in Tab. I, ball milling which was introduced as a preliminary step of the samples preparation increased relative compression $\Delta D / D$ of the $\mathrm{Al}$ powders after HPT consolidation from about 30 to $50 \%$. Also microhardness measured at the center and at the edge of $\mathrm{Al}$ samples increased in both cases from 0.9 to 1.5 and from 1.6 to 2.0 GPa respectively (Table I, line 1 and 2). However, it is also visible that neither $\Delta D / D$ nor $\mu \mathrm{HV}$ changed as a result of the $0.05 \mathrm{wt} \%$ of graphene addition. Also XRD patterns made for Al samples produced in both ways and $\mathrm{Al}+$ graphene sample produced with the same number of $N=5$ rotations did not reveal any differences and could be well fitted to the standard pattern of pure Al (PDF 00-004-0787) (Fig. 2).

The estimation of the deformation range in the case of the HPT is not easy, as many formulae for this were suggested [14]. In this paper the formulae 


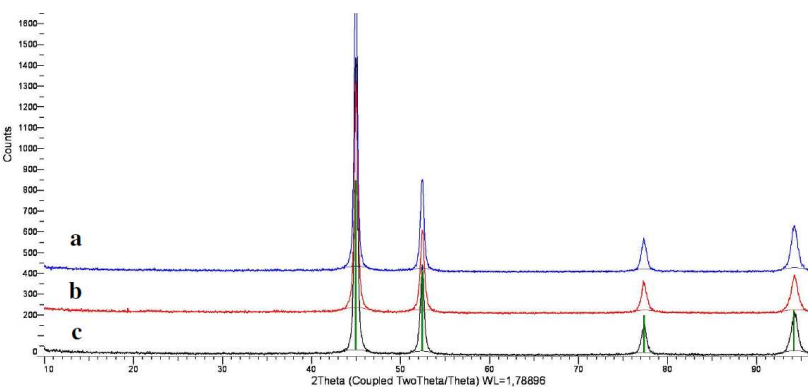

Fig. 2. Comparison of the XRD patterns from the samples: (a) Al produced with ball milling and HPT $(N=5),(\mathrm{b}) \mathrm{Al}$ produced seldom by $\mathrm{HPT}(N=5),(\mathrm{c})$ $\mathrm{Al}+0.05$ wt.\% of graphene, produced by ball milling and $\operatorname{HPT}(N=5)$. Position of Al diffraction lines (PDF 00-004-0787) marked. Line Co $K_{\alpha}$ used.

$$
\gamma=2 \pi \mathrm{N}(\mathrm{R} / \mathrm{D})
$$

and

$$
\varepsilon=\left(2 / 3^{1 / 3}\right) \ln \left(\left(1+\gamma^{2} / 4+\gamma / 2\right)^{1 / 2}\right)
$$

for the shear strain $\gamma$ and the equivalent strain $\varepsilon$ are used, where $\mathrm{D}$ is final thickness and $\mathrm{R}$ - the radius to the deformed point [14]. This gives maximal equivalent strain at the edges of the samples at the level of 7.60 for sample, $N=5$ rotations and 8.30 for the $N=10$ rotations.

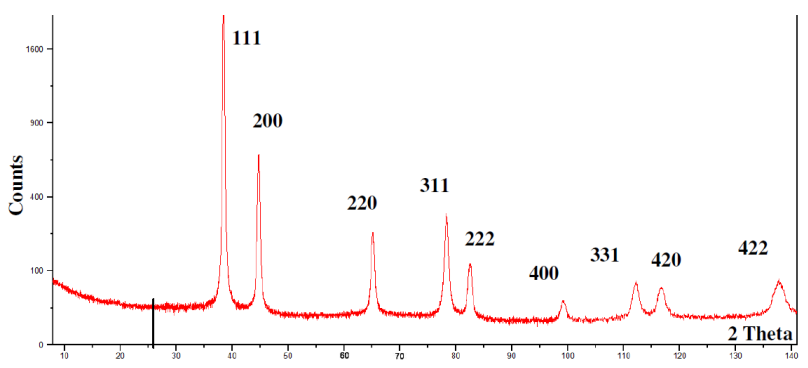

Fig. 3. Precise XRD pattern from the sample Al-5 wt.\% graphene after HPT with $N=5$. Only Al peaks identified. Position of the expected graphene intensities marked. Line $\mathrm{Cu} K_{\alpha}$ was used.

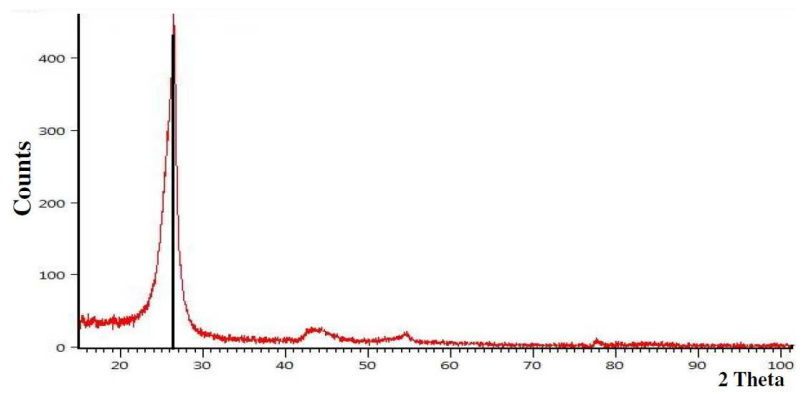

Fig. 4. XRD precise pattern from the sample of graphene used for the composite. Line $\mathrm{Cu} K_{\alpha}$.
The structure of the composite samples containing graphene was further investigated by XRD, SEM, and TEM. The result of the high precision XRD measurements of the $\mathrm{Al}+$ graphene sample prepared by ball milling and HPT with $N=5$ is shown in Fig. 3. For the comparison the graphene sample was also measured in the same way (Fig. 4). The graphene XRD pattern contains one very intensive peak (002) and two others at $26^{\circ}$ and $43^{\circ}$ which may be directly connected with the graphene in the form of nanoplates $[15,16]$. The comparison with the composite XRD pattern in Fig. 3 shows lack of the noticeable intensities which cold be connected with the presence of the graphene. As was shown by Zhou and $\mathrm{Li}$ [17] in case of the Al-graphite composites, ball milling leads quickly to the dissolution of $\mathrm{C}$ in $\mathrm{Al}$ matrix and after 600 min of milling only small trace of the $\mathrm{C}$ (002) peak in the XRD may be observed. In our experiment no traces of the $\mathrm{C}$ (002) peak are visible after $300 \mathrm{~min}$ of MA and HPT process, also no changes in $\mu \mathrm{HV}$ which could result from the solid solution of $\mathrm{C}$ in $\mathrm{Al}$ matrix could be observed (Table I). This may be results of much smaller addition of the graphene than in [17] or of the predominant influence of the intensive deformation on the composite properties.

The microstructure of the composites prepared with $N=5$ and with $N=10$ rotation are presented in Figs. 5-8. Both the SADP and microstructure in Fig. 5a, b show dispersed structure of Al grains. The SADP is typical for the highly deformed microcrystalline sample being composed of the elongated spots. All the rings fit to the pure Al phase. This is also confirmed by the SADP of the monocrystalline character and microstructure in Fig. 6a,b. In Fig. 5c, in slightly de-focused conditions more transparent, bright lenticular or elongated forms are visible, which cannot be connected with the $\mathrm{Al}$ grains themselves. In large magnification this type of microstructure elements is visible in Fig. 6c. Comparison of Figs. 5 and 6 with Figs. 7 and 8a,b, concerning composite prepared with $N=10$ rotations shows much more refined microstructure. The $\mathrm{Al}$ grains are smaller and SADP in Fig. 7b exhibits nearly continuous rings. The same concerns also elements of the microstructure, which may be related to the presence of the graphene, in Figs. 6c and 8c. Unluckily EDS analysis did not reveal local variations in $\mathrm{Al}, \mathrm{C}$ and $\mathrm{O}$ content in the scale of the TEM observations.

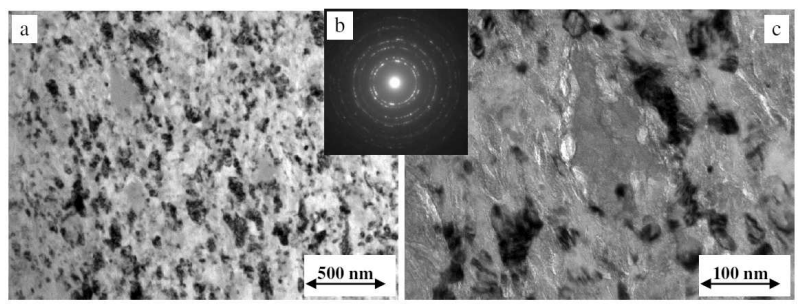

Fig. 5. TEM microstructure of the Al-graphene composite prepared by ball milling and HPT with $N=5$ rot.: (a) small magnification, (b) SADP from Al, (c) light areas between the grains of $\mathrm{Al}$. 


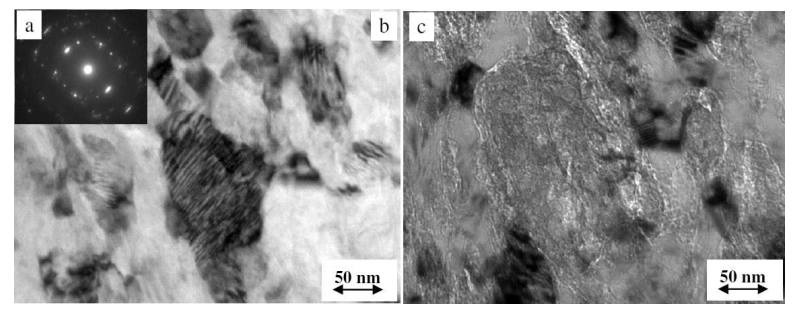

Fig. 6. TEM microstructure of the Al-graphene composite prepared by ball milling and HPT with $N=5$ rot, large magnification: (a) SADP from the $\mathrm{Al}$ grain in contrast, (b) small Al grains, (c) magnification of the light areas between the grains of $\mathrm{Al}$ visible in slightly out-of-focus conditions.

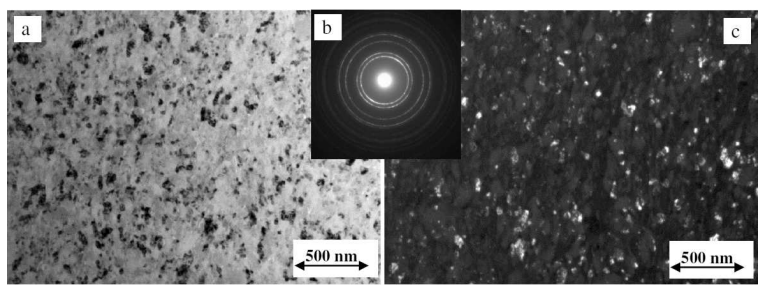

Fig. 7. TEM microstructure of the Al-graphene composite prepared by ball milling and HPT with $N=10$ rot.: (a) BF - small magnification, (b) SADP from Al, (c) DF - the same area, light grains of Al.

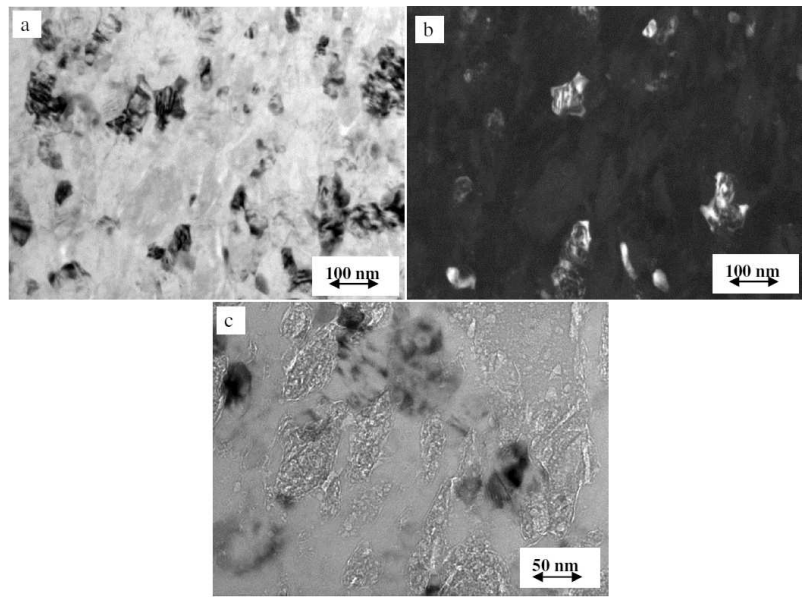

Fig. 8. TEM microstructures of the Al-graphene composite prepared by ball milling and HPT with $N=$ 10 Rot.: (a) BF, Al grains in contrast, (b) DF from the same area, small Al grains bright, (c) larger magnification of the light areas between the grains of $\mathrm{Al}$ visible in slightly out-of-focus conditions.

As both XRD and TEM investigations did not prove the presence of any particular form of carbon, the Raman spectroscopy was used. In Fig. 9a the Raman spectra from the used graphene is shown, while in Fig. 9b-e the image of the observed area identifying the particular points of analysis and the respectful Raman spectra, in case of the sample, produced with $N=5$ rotation are presented. As is visible in Fig. 9a the peak G $\left(1589 \mathrm{~cm}^{-1}\right)$ is intensive while the band $2 \mathrm{D}\left(2650 \mathrm{~cm}^{-1}\right)$ which may be related to the non-defected graphene if single, is very small. The same time peaks named $\mathrm{D}, \mathrm{D}^{\prime}$ and $\mathrm{D}+\mathrm{D}^{\prime}[18]$ are intensive. Such spectra may qualify the used carbon form as very defected, multilayer graphene [19]. In the Raman spectra from the points M1, M2 and M6 (Fig. 9bd) in the bright areas of the matrix, the $\mathrm{D}$ and $\mathrm{G}$ peaks are present while $2 \mathrm{D}$ peak is very small. The $\mathrm{D}$ peak widens but the intensity of $G$ peak increases. Such spectra may be interpreted as resulting both from the increase of the disorder in the multilayer graphene and increasing amount of the graphene non-defected $[18,19]$. In remaining points of analysis (M3, M4, M5) the signal from the carbon remains very weak but the peaks which may be identified with the presence of Al-carbides, especially $\mathrm{Al}_{4} \mathrm{C}_{3}$ are intensive (Fig. 9b,e).

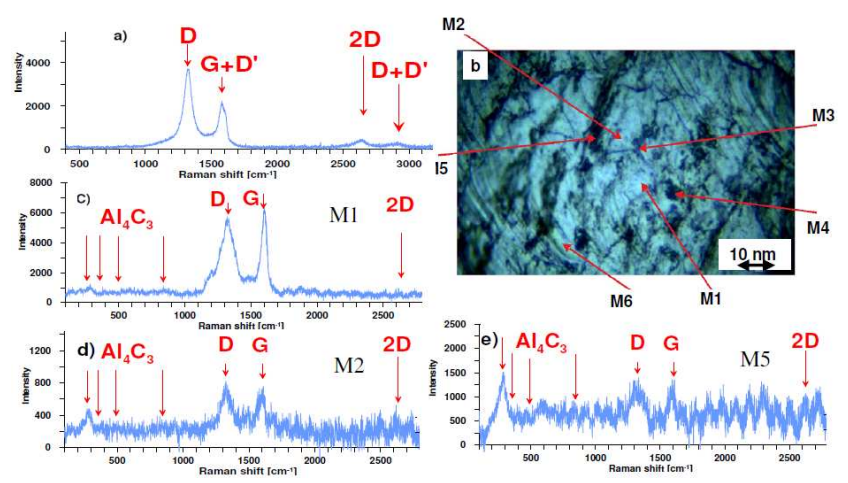

Fig. 9. Sample Al-graphene, $N=5$ rot., Raman spectroscopy: (a) graphene used, (b) position of the investigated points, (c, d) points M1 and M2 in (b) revealing larger content of graphene, (e) dark points revealing small amount or lack of the graphene.

Similar results were achieved in case of the sample produced with the $N=10$ rotations except some differences in the Raman spectra concerning proportion of the $\mathrm{D}$ to $\mathrm{G}$ intensities. In case of the sample passing larger deformation $\Delta D / \Delta G$ increased from 1.9 to 2.6 , which means some increase in the defects density in the multilayer graphene $[19,20]$.

To further elucidate the character of the carbon presence in the composites the photoelectron spectroscopy XPS (ESCA) was used. The XPS enables to determine both the presence of the elements in the materials and the type of the atomic bonding, forming between components. It should be noticed however, that the method is sensitive for the surface layer of the materials. The $10 \mathrm{~min}$ of Ar ion polishing was used to enable studies of the bulk of material. The area of the analysis was $3 \mathrm{~mm}^{2}$. The basic results concerning two samples, $\mathrm{Al}$ and $\mathrm{Al}+0.05$ wt\% graphene, both prepared by mechanical alloying and HPT, with $N=5$ rotations are presented below.

Three types of atoms were determined after ion polishing in both samples: aluminum, carbon, and oxygen. However, in the case of the Al-graphene composite the proportions of elements content: $\mathrm{C} / \mathrm{Al}, \mathrm{O} / \mathrm{Al}$ and $\mathrm{C} / \mathrm{O}$ 
were different than in $\mathrm{Al}$ sample. They are as follows respectively to $\mathrm{Al}+$ graphene/ $\mathrm{Al}$ samples: $\mathrm{C} / \mathrm{Al}-0.05 /$ $0.03, \mathrm{O} / \mathrm{Al}-1.0 / 0.9, \mathrm{C} / \mathrm{O}-0.05 / 0.03$. As results carbon in different forms is present in both samples, but in case of the $\mathrm{Al}+$ graphene sample the content of carbon atoms per aluminum is nearly twice. The other unexpected result is very high content of oxygen atoms in both samples, being nearly 1:1 for the Al atoms. This suggests strong preliminary oxidation of $\mathrm{Al}$ powder or the oxidation process at the step of the mechanical alloying.

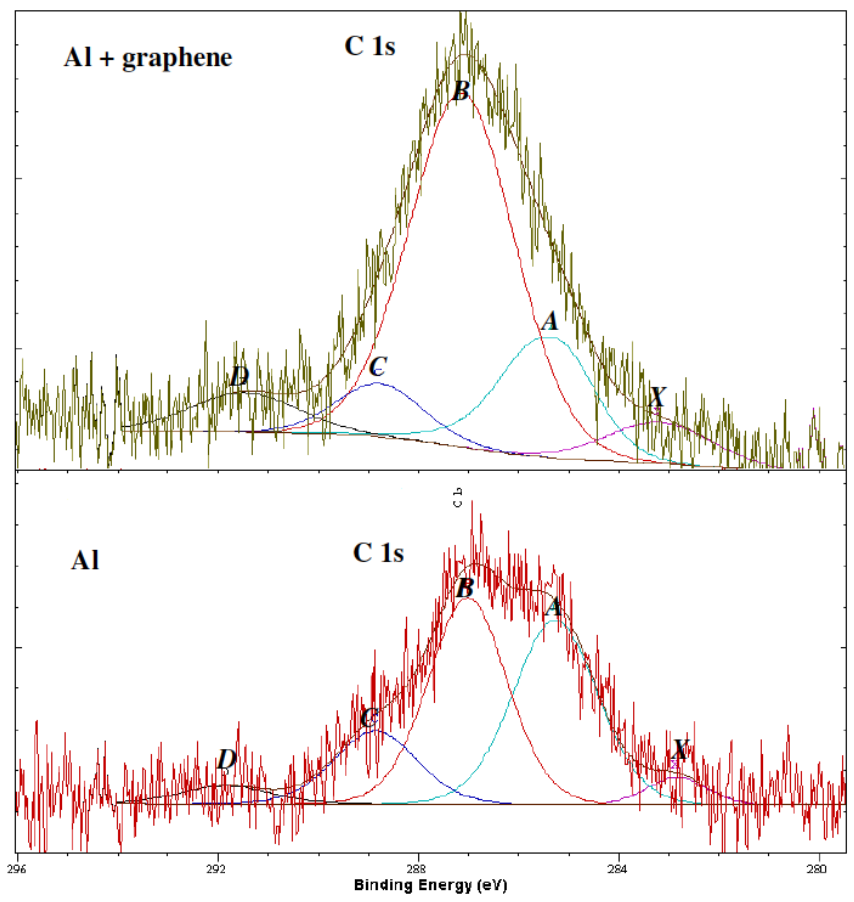

Fig. 10. XPS results for the Al-graphene composite and $\mathrm{Al}$ sample, both prepared the same way by MA and HPT with $N=5, \mathrm{C} 1 \mathrm{~s}$ line. For the components $\mathrm{X}, \mathrm{A}-\mathrm{D}$ explanation - see Table II.

The analysis of the chemical states related to the position of the line components (Figs. 10, 11) was performed on the base of [21-23]. The analysis of $\mathrm{C}$ 1s energy line revealed the following types of the possible carbon bonds (Fig. 10, Table II): C-C - lattice carbon, $\mathrm{C}$ - metal, $\mathrm{C}-\mathrm{O}$ and $\mathrm{C}=\mathrm{O}-$ carbon oxides, also $\mathrm{COOH}$ and $\mathrm{CO}_{3}$ - alcohol or carbonyl groups. The decomposition of the $\mathrm{C}$ 1s electrons spectra leads to the conclusion that the component $\mathrm{C}$-metal is twice larger in the case of the composite with graphene than in the Al ball milled and HPT consolidated sample (Table II). The carbonyl and alcohol types of bonds are also much more frequent in case of this composite, suggesting that the carbon product introduced to the sample contained except graphene also graphite oxide and the organic substances used for the graphene production. The explanation for the carbonoxygen type of bonds $\mathrm{C}-\mathrm{O}, \mathrm{C}=\mathrm{O}$ could be also oxidation of carbon in the composite preparation procedure, as oxy-



Fig. 11. XPS results for the Al-graphene composite and $\mathrm{Al}$ sample prepared in the same way by MA and HPT $N=5$, Al $2 p$ line. For the components A, A', B, $\mathrm{B}^{\prime}$ and $\mathrm{C}$ explanation - see Table II.

gen was available in the form of $\mathrm{Al}$ oxide. On the other hand, sample with graphene reveals much less of the $\mathrm{C}-\mathrm{C}$ carbon lattice bonds than in case of $\mathrm{Al}$ sample.

The analysis of the bonds formed by Al atoms (Fig. 11, Table II) suggests participation of the $\mathrm{Al}-\mathrm{Al}$ bonds and the presence of atoms on the $\mathrm{Al}^{3+}$ valence state. The last may suggest bonding of the $\mathrm{Al}$ atoms with carbon and oxygen rather than simple Al-carbides. The result concerning existence of the $\mathrm{Al}^{3+}-\mathrm{O}$ bonds relates to the high amount of oxygen detected, reported above.

Presented results of XPS suggest formation of the $\mathrm{Al}$ $\mathrm{C}$ and $\mathrm{Al}-\mathrm{C}-\mathrm{O}$ bonds, more intensive in the case of the graphene- $\mathrm{Al}$ composite than in $\mathrm{Al}$ sample, which also contains some carbon atoms revealing tendency to form $\mathrm{C}-\mathrm{C}$ bonds. The other results like intensive $\mathrm{Al}$ and $\mathrm{C}$ oxidation and the presence of the different organic groups may be surface effects or results from the preparation procedure, e.g. organic liquids used at the mechanical alloying step. The large amount of oxygen atoms, nearly 1:1 in both samples was neither revealed by XRD nor by TEM and is also probably predominantly surface oxidation, even if some $\mathrm{Al}$ and $\mathrm{C}$ oxides were introduced with the components. The presence of the $\mathrm{Al}$ carbides was detected also by the Raman spectroscopy results.

There is strong suggestion however that the HPT promotes also formation of the $\mathrm{Al}-\mathrm{C}$ bonds of another type. The problem of the chemical bonds forming between aluminum and carbon in the Al based composites needs a modified preparation method, reducing the lattice carbon 
TABLE II

XPS results for the Al-graphene composite and consolidated $\mathrm{Al}$ samples prepared in the same way by MA and HPT, with $N=5$ : C $1 s$ and Al $2 p$ lines positions, relative areas and hypothetical interpretation of the lines components.

\begin{tabular}{|c|c|c|c|c|}
\hline & Name & $\begin{array}{l}\text { Bond } \\
\text { type }\end{array}$ & $\begin{array}{c}\text { Position } \\
{[\mathrm{eV}]}\end{array}$ & $\begin{array}{c}\text { Area } \\
{[\%]}\end{array}$ \\
\hline & \multicolumn{4}{|c|}{ C $1 s$} \\
\hline \multirow{5}{*}{$\begin{array}{c}\text { Al sample } \\
\text { consolidation }\end{array}$} & $\mathrm{X}$ & C-metal & 282.8 & 3.9 \\
\hline & A & $\mathrm{C}-\mathrm{C}$ & 285.3 & 38.0 \\
\hline & B & $\mathrm{C}-\mathrm{O}+\mathrm{C}=\mathrm{O}$ & 287.0 & 39.7 \\
\hline & $\mathrm{C}$ & $\mathrm{COOH}$ & 288.9 & 14.7 \\
\hline & $\mathrm{D}$ & $\mathrm{CO} 3$ & 291.9 & 3.7 \\
\hline \multirow{6}{*}{$\begin{array}{l}\text { Al-graphene } \\
\text { composition }\end{array}$} & $\mathrm{X}$ & C-metal & 283.2 & 7.0 \\
\hline & A & $\mathrm{C}-\mathrm{C}$ & 285.3 & 18.6 \\
\hline & B & $\mathrm{C}-\mathrm{O}+\mathrm{C}=\mathrm{O}$ & 287.1 & 60.1 \\
\hline & $\mathrm{C}$ & $\mathrm{COOH}$ & 288.8 & 7.5 \\
\hline & $\mathrm{D}$ & $\mathrm{CO} 3$ & 291.5 & 6.8 \\
\hline & \multicolumn{4}{|c|}{ Al $2 p$} \\
\hline \multirow{5}{*}{$\begin{array}{c}\text { Al sample } \\
\text { consolidation }\end{array}$} & $\bar{A}$ & \multirow{2}{*}{$\mathrm{Al}-\mathrm{Al}$} & 73.6 & 34.2 \\
\hline & $\mathrm{A}^{\prime}$ & & 74.0 & 0.0 \\
\hline & B & \multirow{2}{*}{$\mathrm{Al}^{3+}-\mathrm{O}$} & 76.8 & 64.5 \\
\hline & $\mathrm{B}^{\prime}$ & & 77.2 & 0.0 \\
\hline & $\mathrm{C}$ & $\mathrm{Al}^{3+}-$ & 79.5 & 1.3 \\
\hline \multirow{5}{*}{$\begin{array}{l}\text { Al-graphene } \\
\text { composition }\end{array}$} & $\mathrm{A}$ & \multirow{2}{*}{$\mathrm{Al}-\mathrm{Al}$} & 73.5 & 28.7 \\
\hline & $\mathrm{A}^{\prime}$ & & 73.9 & 0.0 \\
\hline & B & \multirow{2}{*}{$\mathrm{Al}^{3+}-\mathrm{O}$} & 76.9 & 69.0 \\
\hline & $\mathrm{B}^{\prime}$ & & 77.3 & 0.0 \\
\hline & $\mathrm{C}$ & $\mathrm{Al}^{3+}-$ & 78.8 & 2.3 \\
\hline
\end{tabular}

and oxygen content and further investigations.

\section{Summary and Conclusions}

The consolidated aluminum samples and aluminumgraphene composites were produced with use of two step technique: first mechanical alloying of $\mathrm{Al}$ and graphene powders and later the intensive deformation by HPT. As a result small, thin and round samples, about $10 \mathrm{~mm}$ in diameter were achieved.

The MA introduced before HPT leads to the increased compression and microhardness of the samples achieved in the similar HPT deformation. The further increase in the deformation range and resulting structure refinement was achieved by the increase of the rotation number with the same hydrostatic pressure preserved. The XRD and TEM did not directly reveal graphene in the microstructure composed of the fine Al grains.

The results of the Raman spectroscopy suggested multilayer graphene with large disorder which could also be identified as nanographite and some amount of less defected graphene introduced by the HPT, both as components of the composite structure as well as some small content of the aluminum carbides.
The XPS method revealed carbon and aluminum oxides in large amounts which is interpreted as a surface effect. The XPS method suggested also formation of the carbon-metal and carbon-metal-oxygen atomic bonds, which may be partially the result of the carbides formation but may be also indication of the incorporation of the graphene, at least partially to the atomic structure of the composite by the HPT method.

For the further improvement of the Al-graphene composites achieved by the MA and subsequent HPT, elimination of the possibility of oxidation of $\mathrm{Al}$ and $\mathrm{C}$ as well as reduction of the amount of carbon introduced not intentionally by the preparation processes should be undertaken.

\section{Acknowledgments}

The work was financed by the Project GRAF$\mathrm{TECH} / \mathrm{NCBR} / 10 / 29 / 2013$ and partially realized in frame of the bilateral cooperation project between IMMS PAS and IMSP RAS 2014-2016.

\section{References}

[1] K.S. Novoselov, A.K. Geim, S.V. Morozov, D. Jiang, Y. Zhang, S.V. Dubonos, I.V. Grigorieva, A.A. Firsov, Science 306, 666 (2004).

[2] A.K. Geim, Science 324, 1530 (2009).

[3] A.K. Geim, K.S. Novoselov, Nature Mater. 6, 183 (2007).

[4] K.S. Novoselov, Z. Jiang, Y. Zhang, S.V. Morozov, H.L. Stormer, U. Zeitler, J.C. Maan, G.S. Boebinger, P. Kim, A.K. Geim, Science 315, 1379 (2007).

[5] C.G. Rocha, M.H. Rümmeli, I. Ibrahim, H. Sevincli, F. Börrnert, J. Kunstmann, A. Bachmatiuk, M. Pötschke, W. Li, S.A.M. Makharza, S. Roche, B. Büchner, G. Cuniberti, in: Graphene, Synthesis and Applications, Eds. W. Choi, J. Lee, CRC Press, Boca Raton 2012, p. 1.

[6] C.G. Lee, X.D. Wei, J.W. Kysar, J. Hone, Science 321, 385 (2008).

[7] D. Lahiri, A. Agarwal, in Ref. [5], p. 188.

[8] C.G. Rocha, F. Ortmann, A. Cresti, B. Biel, D. Jimenez, in Ref. [5], p. 10.

[9] S. Pei, H-M. Cheng, Carbon 50, 3210 (2011).

[10] T. Otsuji, T. Suemitsu, A. Satou, M. Suemitsu, E. Sano, M. Ryzhii, V. Ryzhii, in Ref. [5], p. 85.

[11] R.Z. Valiev, A.P. Zhilyaev, T.B. Langdon, in: Bulk Nanostructured Materials, TMS Wiley, Hoboken (NJ) 2014, p. 88.

[12] J. Sort, D.C. Ile, A.P. Zhilyaev, A. Concustell, T. Czeppe, M. Stoica, S. Surinach, J. Eckert, M.D. Baró, Scr. Mater. 50, 1221 (2004).

[13] T. Czeppe, G.F. Korznikova, A.W. Korznikov, L. Litynska-Dobrzynska, Z. Światek, Arch. Metall. Mater. 58, 447 (2013).

[14] R.Z. Valiev, A.P. Zhilyaev, T.B. Langdon, in Ref. [11], p. 30 .

[15] M.L. Chen, Ch-Y. Park, J-G. Choi, W-Ch. Oh, J. Korean Ceramic Soc. 48, 147 (2011). 
[16] G. Wang, J. Yang, J. Park, X. Gou, B. Wang, H. Liu, J. Yao, J. Phys. Chem. C 112, 8192 (2008).

[17] Y. Zhou, Z.Q. Li, J. Alloys Comp. 414, 107 (2006).

[18] A.C. Ferrari, J.C. Meyer, V. Scardaci, C. Casiraghi, M. Lazzeri, F. Mauri, S. Piscanec, D. Jiang, K.S. Novoselov, S. Roth, A.K. Geim, Phys. Rev. Lett. 97, 187401 (2006).

[19] Ado Jorio, Raman Spectroscopy in Graphene Based Systems: Prototypes for Nanoscience and Nanometrology, ISRN Nanotechnology, 2012.

[20] I. Childres, L.A. Jauregui, W. Park, H. Cao, Y.P. Chen, in: New Developments in Photon and $M a-$ terials Research, Eds. J.I. Jang, Nova Science Pub Inc, Hauppauge (NY) 2013, Ch. 13.
[21] J.F. Moulder, W.F. Stickle, P.E. Sobol, K. Bomben, Handbook of X-ray Photoelectron Spectroscopy, Ed. J. Chastain, 2nd ed., Perkin-Elmer Corporation (Physical Electronics), Waltham (MA) 1992.

[22] Electron Spectroscopy Database; http://lasurface.com .

[23] NIST X-ray Photoelectron Spectroscopy Database; http://srdata.nist.gov/xps/. 